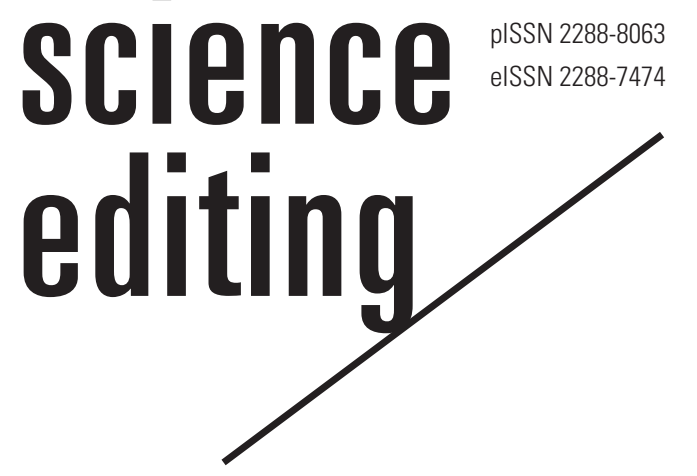

\title{
Pattern of reference types and impact factors of journals in the Korea Citation Index according to academic discipline
}

\author{
So-Hyeong Kim \\ National Research Foundation of Korea, Daejeon, Korea
}

\section{Abstract}

The Korea Citation Index (KCI) is a citation database for scholarly journals from Korea, the number of journals of which is 2,168 in January, 2015. This article aims to analyze the pattern of reference types and impact factors of journals in the KCI according to academic discipline. Journals of the KCI were classified according to academic discipline: humanities, arts and sports, social science, science, and multi-disciplinary science. Science journals were sub-classified as natural science, engineering, agriculture $\&$ fisheries, and medical health. The pattern of reference types was classified as journal article, book, report/thesis/internet, and others. Changing patterns of the two-year impact factor were described according to the publication year of journals in each discipline. The reference type of each discipline in 2010 showed different patterns. In humanities, the portion of books out of cited literatures was $51.1 \%$, while the portion of books in natural science, engineering, medical health, and agriculture \& fisheries fields were $11.0 \%, 10.0 \%, 7.0 \%$, and $11.0 \%$, respectively. In social science, the portion of journal articles was $53.1 \%$ and books $27.3 \%$. In medical health, the portion of journal article was $87.6 \%$. Journals' average impact factors in 2011 were 0.9 for social science, 0.8 for arts and sports, 0.55 for interdisciplinary, 0.5 for agriculture and fisheries and humanities, 0.45 for natural science, 0.32 for engineering, and 0.3 for medical health. Researchers in humanities in Korea use books as a primary source of references, while those in other disciplines use journals as a major source of references. Higher impact factors in social science journals and lower ones in science journals mean that social scientists in Korea deal with mainly domestic topics, while scientist deal with global topics.

Received: January 16, 2015 Accepted: January 30, 2015

Correspondence to So-Hyeong Kim mini@nrf.re.kr

ORCID

So-Hyeong Kim

http://orcid.org/0000-0002-3973-6782
Keywords

Books; Internet; Journal impact factor; Republic of Korea 


\section{Introduction}

The Korea Citation Index (KCI) is a literature citation database maintained by the National Research Foundation of Korea (NRF), which comprises of scholarly journals published in Korea [1]. It began to gather the journal literature information starting from 1998. It comprises of $1,075,690$ articles and the $16,904,495$ references listed in them. The KCI has characteristics as follows: first, journal data are gathered automatically, as publishers of each journal deposit article files to the KCI within 14 days after publication; second, article file deposit to the $\mathrm{KCI}$ is allowed only to those journals that passed the selection criteria set by the NRF of Korea and are designated as accredited journals or candidate journals; and third, the KCI is linked to the database of the Korean Researchers Information (KRI) which are linked to their affiliatio ns' databases for researchers' achievements. The searching service of the KCI on the web was launched in 2008. As a product manager of the KCI, I would like to show some interesting analyses on the reference types and the impact factor according to academic discipline and publication year.

\section{Methods}

The number of journals included in the KCI according to the discipline was shown in Table 1. There were 1,762 accredited journals and 406 candidate journals for accreditation in January, 2015. Total 16,904,495 references from 1,075,690 articles in the KCI were classified into four types: journal article, book, report/thesis/internet, and others. The two-year impact factor was calculated according to the following formula:

Number of cites by KCI articles published in 2011 to journal articles published in $2009=\mathrm{A}$

Number of cites by KCI articles published in 2011 to journal articles published in $2010=\mathrm{B}$

Table 1. Number of accredited and candidate journals in Korea Citation Index up to January 2015

\begin{tabular}{lccccc}
\hline Disciplines & Societies (A) & Accredited & Candidate & Total (B) & B/A (\%) \\
\hline Humanities & 763 & 460 & 81 & 541 & 71 \\
Social science & 1,216 & 604 & 161 & 765 & 63 \\
Science $^{\text {a) }}$ & 965 & 553 & 109 & 662 & 69 \\
Arts and sports & 266 & 91 & 33 & 124 & 47 \\
Interdisciplinary & 200 & 54 & 22 & 76 & 38 \\
Total & 3,410 & 1,762 & 406 & 2,168 & 64 \\
\hline
\end{tabular}

a) Science comprises natural science (mathematics, physics, chemistry, biology, and earth science), engineering, agriculture and fisheries, and medical health.
Sum $=A+B$

Number of KCI articles published in $2009=\mathrm{C}$

Number of KCI articles published in $2010=\mathrm{D}$

Sum $=\mathrm{C}+\mathrm{D}$

2011 Impact factor $=(A+B) /(C+D)$

The impact factor of journals was classified according to the academic discipline from 2008 to 2011.

\section{Results}

\section{Reference types}

The reference types according to academic discipline from the $2010 \mathrm{KCI}$ data were shown in Fig. 1. In all disciplines, journal articles were the main reference type, followed by books except in humanities. In humanities, the portion of books in cited references was more than $51.1 \%$, while the portion of books in natural science, engineering, medical health, and agriculture and fisheries were $11.0 \%, 10.0 \%, 7.0 \%$, and $11.0 \%$ respectively. The proportion of journal articles was $87.6 \%$ in medical health fields. In social science, the portion of journal articles was $53.1 \%$ and books $27.3 \%$. Out of all reference types from all fields, the internet data had increased continuously from 2008 to $2010,1.6 \%, 2.2 \%, 2.4 \%$, and $2.5 \%$, respectively, while the portion of books had decreased gradually from 2008 to $2010,27.0 \%, 25.4 \%, 24.3 \%$, and $24.3 \%$, respectively.

\section{Impact factor}

The impact factor had been increasing in every discipline, as

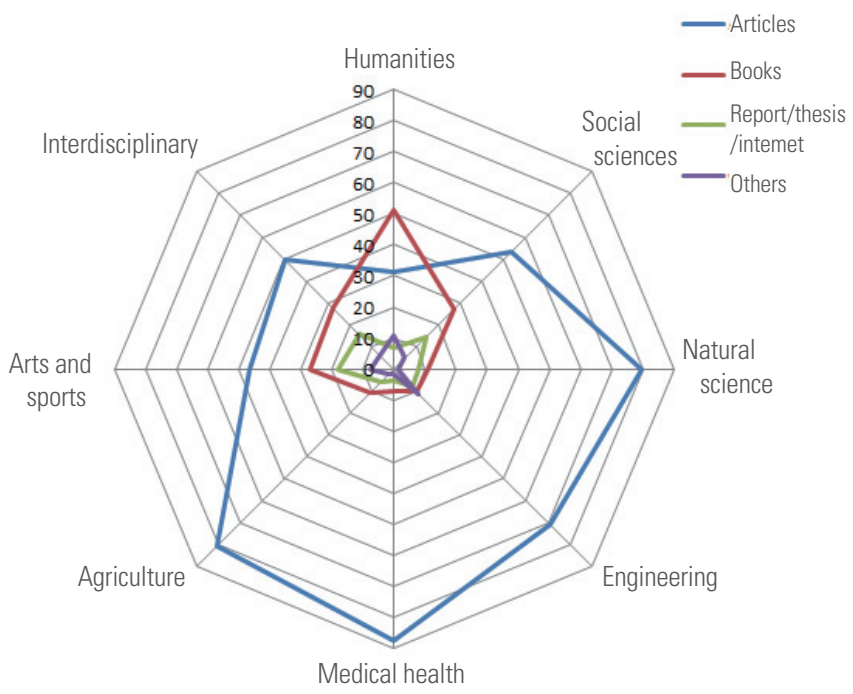

Fig. 1. Pattern of reference types of journals from 2010 Korea Citation Index according to disciplines. 


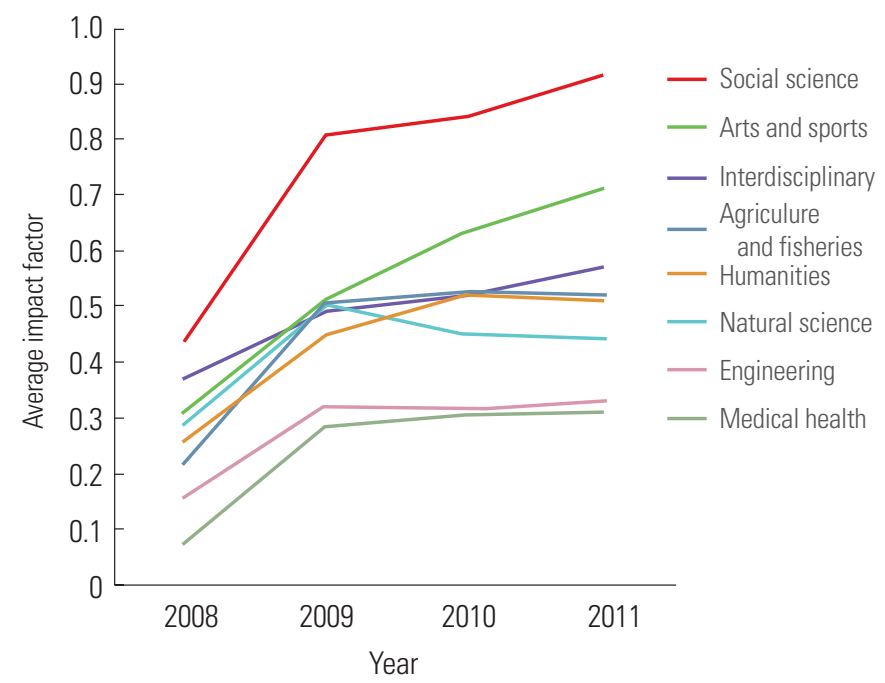

Fig. 2. Chronological change of average impact factors of journals in Korea Citation Index from 2008 to 2011 according to academic discipline.

Table 2. Number of journals of which impact factor was greater than 1.2 in Korea Citation Index from 2008 to 2010

\begin{tabular}{lcccc}
\hline \multirow{2}{*}{ Fields } & \multicolumn{4}{c}{ Year } \\
\cline { 2 - 5 } & 2008 & 2009 & 2010 & 2011 \\
\hline Humanities & 1 & 23 & 50 & 38 \\
Social science $_{\text {Natural science }}{ }^{\text {a) }}$ & 10 & 84 & 104 & 126 \\
Engineering $^{\text {Medical health }}$ & 1 & 6 & 7 & 8 \\
Agriculture and fisheries & 0 & 4 & 2 & 1 \\
Arts and sports & 0 & 4 & 7 & 6 \\
Interdisciplinary & 0 & 2 & 3 & 2 \\
Total & 1 & 9 & 8 & 11 \\
\hline
\end{tabular}

a) Natural science comprises mathematics, physics, chemistry, biology, and earth science.

shown in Fig. 2. The number of journals, of which impact factor was greater than 1.2, grew from 13 in 2008 to 195 in 2011 (Table 2). These journals made up $17.1 \%$ of social sciences and $8.9 \%$ of arts and sports (Fig. 3).

\section{Discussion}

From the results on the reference types described above, it can be said that researchers in humanities in Korea use books as a primary source of references, while scientists use journal articles as a major source of references. Medical health research-

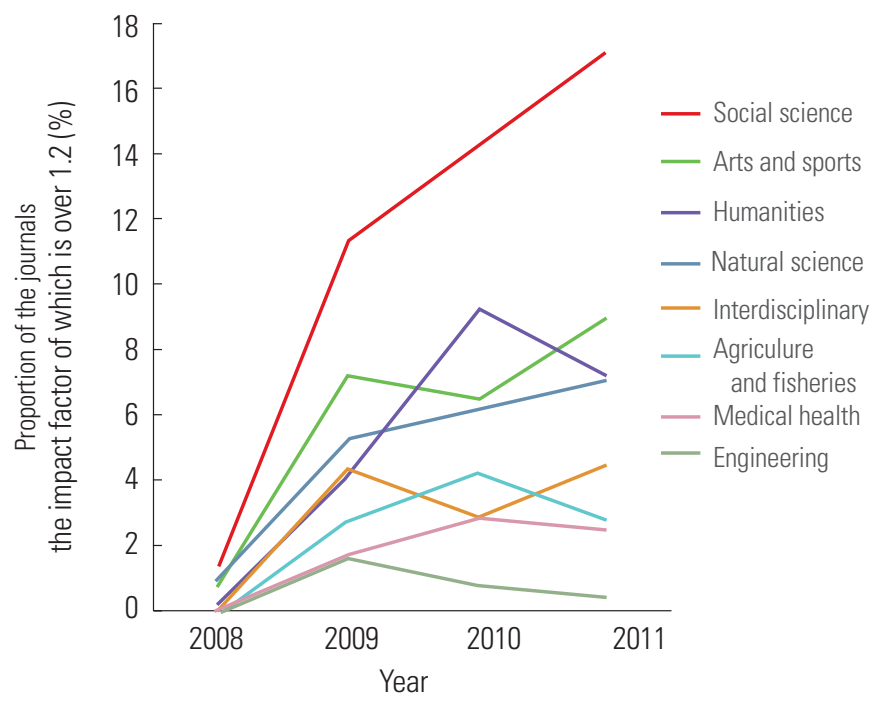

Fig. 3. Proportion of journals of which impact factor was greater than 1.2 in Korea Citation Index from 2008 to 2011 according to academic discipline.

ers cite journal articles as their references most frequently, because the progress of the knowledge and technology is so rapid that more recent information can be obtained from journal articles rather than from books, reports, or theses. The chronological increase of journal impact factors in the KCI can be explained by several factors. First, the number of accredited journals and papers has increased, therefore a greater number of articles has been exposed to and cited by others. Second, the style and format of the KCI journals has been periodically checked by the NRF so that the references have become more precise. Third, the database quality has increased sufficiently owing to the link between the KRI and the KCI databases that it is now possible to detect small errors. Fourth, the most important thing may be the search function of the KCI that helps researchers to find relevant references from the journals published in Korea. The increase of the impact factor told us that the KCI did its role as an infrastructure for research in Korea.

The higher proportion of social science journals out of the $\mathrm{KCI}$ journals, of which impact factor was greater than 1.2 may be due to the following reasons: first, the number of the KCI journals in social science field (765) is the greatest among all disciplines; second, social scientists in Korea use journal articles for $53.1 \%$ of their references; and third, social scientists usually deal with domestic topics rather than global topics. On the contrary, scientists usually deal with universal topics, because the methods and materials can be the same to all international researchers. Therefore scientists cite foreign journal articles more frequently, the number of which exceeds that of domestic journal articles. 
The KCI had been initially used for internal purposes of the NRF, such as bibliometrics and journal evaluation. The KCI has been a web-based searching database to provide the research products from the journals in Korea since 2008. From May 6, 2014, the KCI database became available from Web of Science, literature citation database maintained by Thomson Reuters so that the literature from Korea can be propagated through an international platform [2]. The KCI will aid in our understanding of weaknesses and strengths of specific fields in Korea. There are a variety of researches covered by the KCI. S-index, which is a novel evaluation index based on the number of citations of each article in a particular journal and the rank of the article according to the number of citations was suggested and tested in the KCI [3]. Kor-Factor was also suggested as a powerful tool for evaluating journals in the KCI [4]. Further researches with KCI data are highly recommended by the NRF.

The following conclusions can be deduced from the results described above. First, there was a heavy reliance on books for researchers in humanities; however, journal articles were main references in all other disciplines. Second, the impact factor has trended upward in all disciplines. The impact factor was highest in social science fields, which could be due to a large number of social science journals in the KCI and the domestic research topics that social scientists usually deal with. Third, low impact factors in science fields, especially in medical health fields, could be explained by the fact that the topics in these fields were global and universal rather than specific to domestic needs.

\section{Conflict of Interest}

Author is a product manager of KCI database who presides over the schema construction, data input and out, web design, and analysis of the results. It is based on the author's opinion and does not reflect the official opinion of the NRF.

\section{Acknowledgments}

This work is supported by a research grant from the National Research Foundation of Korea (policy research-2012-064-academic infrastructure promotion).

\section{References}

1. National Research Foundation of Korea. Korea Citation Index [Internet]. Seoul: National Research Foundation of Korea; 2008-2015 [cited 2015 Jan 15]. Available from: http://kci.go.kr

2. Thomson Reuters. Thomson Reuters collaborates with National Research Foundation of Korea to showcase the region's research in Web of Science [Internet]. Philadelphia, PA: Thomson-Reuters; 2015 [cited 2015 Jan 15]. Available from: http://thomsonreuters.com/press-releases/052014/Thomson-Reuters-Nationa-Research-Foundation-Korea

3. Ko YM, Park JY. An index for evaluating journals in a small domestic citation index database whose citation rate is generally very low: a test based on the Korea Citation Index (KCI) database. J Informetr 2013;7:404-11. http:// dx.doi.org/10.1016/j.joi.2013.01.002

4. Ko YM, Cho SR, Park YS. A study on the optimization of KCI-based index (Kor-Factor) in evaluating Korean journals. Scientometrics 2011;88:61-71. http://dx.doi.org/10.1007/ s11192-011-0384-Z 